\title{
PHYSICAL ACTIVITY OF POLISH AND TURKISH UNIVERSITY STUDENTS AS ASSESSED BY IPAQ
}

\author{
Justyna Bednarek, 1 , A, B, C, D, E Sylwia Pomykała, ${ }^{1, A, B, E}$ Monika Bigosińska, ${ }^{2, C, D}$ \\ Zbigniew Szyguła, D
}

\footnotetext{
1 University School of Physical Education, Kraków, Poland

${ }^{2}$ Department of Physical Education, Institute of Physical Education, State Higher Vocational School, Nowy Sacz, Poland

${ }^{3}$ Department of Sport Medicine and Human Nutrition, Institute of Human Physiology, University School of Physical Education, Kraków, Poland

A Study Design; ${ }^{\mathrm{B}}$ Data Collection; ${ }^{\mathrm{C}}$ Statistical Analysis; ${ }^{\mathrm{D}}$ Manuscript Preparation; ${ }^{\mathrm{E}}$ Funds Collection
}

\author{
Address for corpespondence: \\ Justyna Bednarek \\ University School of Physical Education, Department of Sport Medicine and Human Nutrition \\ Jana Pawła II Ave 78, 31-571 Kraków, Poland \\ E-mail: bednarekjustyna1@gmail.com
}

\begin{abstract}
Ahstract Purpose: We examine physical activity levels of Polish and Turkish students to determine cross-cultural and gender differences in exercise habits.

Methods: Our study assessed 50 students from Adnan Menderes University in Aydin, Turkey and 50 students from the University of Physical Education in Krakow, Poland. Physical activity was measured using the International Physical Activity Questionnaire (IPAQ; short form). Results were expressed in MET-minutes/week (Metabolic Equivalent of Task).

Results: More than half of the students $(52 \%)$ engaged in moderate physical activity in the week prior to the survey, while a quarter of the students $(37 \%)$ engaged in vigorous physical activity. Low levels of physical activity were reported by $11 \%$ of the students. Total physical activity per week, expressed in MET-minutes/week, was significantly higher for Polish students (5,953.51 MET) than for Turkish students (3,095.45 MET). Moderate physical activity was higher among Turkish students while vigorous physical activity was higher among Polish students. Physical activity contrasts were further exemplified between genders. Polish women engaged in significantly more $(p<0.05)$ total physical activity than Turkish women. Total physical activity, high-level physical activity, and moderate-level physical activity differences were not significant $(p>0.05)$ between Polish and Turkish men.

Conclusion: Polish university students engage in more physical activity than students from Turkey. Men were more physically active in both countries. More than half of Turkish students do not meet minimum weekly physical activity the World Health Organization recommends for preserving health.
\end{abstract}

Key WOrlls students, physical activity, IPAQ

\section{Introduction}

Physical activity is both an important component of social health (Booth, 2001; Bruunsgaard, 2005; Drygas, Jegier, Bednarek-Gejo, Kostka, 2005). Though physical activity is linked to general health and well-being, and is frequently associated with morbidity and mortality prevalence and severity, its role remains underestimated 
(Janssen, Leblanc, 2010). Regular physical activity provides many health benefits, such as positive impact on quality of life and reduction in the risk of cardiovascular and metabolic diseases, including atherosclerosis, stroke, arthritis, diabetes, osteoporosis and some forms of cancer (Haskell et al., 2007; Nelson et al., 2007; Malina, Katzmarzyk, 2006). Physical activity can also reduce stress and anxiety, and can improve sleep quality (Penedo, Dahn, 2005). Moreover, physical activity, when regimented properly, positively affects physiological parameters that characterize health, such as physical fitness, body composition and lipid profiles (Drygas, Jegier, Bednarek-Gejo, Kostka, 2005; Zoeller, 2007). A sedentary lifestyle facilitates slowing of the body's metabolism and deterioration of metabolic function, as well as decline in both specific and nonspecific immune systems, physical fitness and mental health (Katzmarzyk, Church, Craig, Bouchard, 2009; Touvier et al., 2010).

However, recent trends show that regular physical activity is lacking among many populations around the world (Zatoński, 2011). Thus, it is imperative that we better understand the underlying patterns and drivers of physical activity to improve human well-being at both individual and societal levels. This can be best achieved by employing physical activity assessments at myriad demographic scales across both cultures and countries. Yet currently there exists a paucity of such comparative analyses due to inconsistencies in measurement methods that confound potential elucidations regarding physical activity and its effect on health (van Bottenburg, Rijnen, van Sterkenburg, 2005). Without a universal, systematic approach, conceptual and terminological pitfalls may be introduced as well (Narring, Cauderay, Cavadini, Michaud, 1999). Therefore, studies should aim to harmonize methodological procedures through the use of recognized, proven and standardized testing instruments (Mussino, 1999).

In recent years, international health communities, such as the European Health Interview Survey (EUROHIS), the European Physical Activity Surveillance System (EUPASS) and the European Social Survey 2002 ("www. ess.nsd.uib.no"; "www.healthcanada.ca/paguide Handbook for Canada's physical activity guide to healthy active living, Health Canada, Canadian Society for Exercise Physiology"), have galvanized their efforts by recommending the International Physical Activity Questionnaire (International Physical Activity Questionnaire, IPAQ) as the universal assessment for measuring physical activity ("www.ipaq.ki.se"). IPAQ was developed according to strict methodological rules that allow for country-to-country physical activity comparisons. The questionnaire is adapted to the relative conditions of each included country, accounting for lifestyle and cultural disparities (Craig et al., 2003). IPAQ is particularly preferred due to its strictly uniform terms and concepts, which are translated into multiple languages for use on a global scale.

Here, we compare physical activity habits of university students in Krakow, Poland with those in Aydin, Turkey to increase comprehension related physical activity patterns on international scales. The questions addressed in this work are: (1) Are there significant physical activity differences between students from Poland and Turkey? and (2) Are there significant physical activity differences between genders in both Poland and Turkey?

\section{Materials and methods}

We surveyed 50 undergraduate university students from both Adnan Menderes University in Aydin, Turkey (36 females and 14 males) and the University of Physical Education in Krakow, Poland ( 25 females and 25 males). Participants from both universities were enrolled in their respective Tourism and Recreation programs and were of similar ages (18-21 years old). A detailed characterization of the groups is shown in Table 1. 
Table 1. Characteristics of participants

\begin{tabular}{lcccccc}
\hline \multirow{2}{*}{ Nationality } & \multicolumn{2}{c}{ Women } & \multicolumn{2}{c}{ Men } & \multicolumn{2}{c}{ Total } \\
\cline { 2 - 7 } & $\mathrm{n}$ & $\%$ & $\mathrm{n}$ & $\%$ & $\mathrm{~N}$ & $\%$ \\
\hline Poland & 25 & 25 & 25 & 25 & 50 & 50 \\
Turkey & 36 & 36 & 14 & 14 & 50 & 50 \\
Total & 61 & 61 & 39 & 39 & & \\
\hline
\end{tabular}

Each participant's level of physical activity (PA) was measured using the International Physical Activity Questionnaire (IPAQ - short form). Participants reported the frequency (days per week) and duration (hours) of walking, moderate and vigorous physical activity that they engaged in during the week prior to survey. Vigorous physical activity, defined by the questionnaire, referred to intense exercise that resulted in very rapid breathing and an elevated heart rate (e.g. intense weight lifting, aerobics, running, and cycling). Moderate physical activity was defined as less intense exercise that slightly heightened breathing and heart rate (e.g. less exertive cycling, fast walking, and light weight lifting). Participants were asked only to report physical activity that exceeded ten minutes in duration. Physical activity data were converted to Metabolic Equivalent of Task units (MET-minutes/ week) by multiplying the number of exercise minutes per day by the number of exercise days per week by the MET coefficient of exercise intensity (vigorous PA = $8 \mathrm{MET}$, moderate PA = $4 \mathrm{MET}$, walking PA = 3.3 MET). The MET coefficient of exercise intensity corresponds to an individual's oxygen consumption during physical activity relative to oxygen consumption at rest $\left(3.5 \mathrm{ml} \mathrm{O}_{2}\right.$ per $\mathrm{kg}$ of body weight per minute). Questionnaires were scored using established methods posted on the IPAQ website (www.ipaq.ki.se). Respondents were then classified into groups (high, moderate, and low physical activity) based on the following criteria:

1. High physical activity - three or more days of vigorous physical exercise, including at least 1,500 MET-minutes/week, or seven or more days of any combination of vigorous exercise, moderate exercise, and walking that exceeded 3,000 MET-minutes/week.

2. Moderate physical activity - three or more days of vigorous physical exercise (at least 20 minutes per day), or five or more days of moderate exercise or walking (at least 30 minutes per day), or five or more days of a combination of vigorous exercise, moderate exercise, and walking that exceeded 600 MET-minutes/ week.

3. Low physical activity - Little physical activity that resulted in a failure to comply with the conditions of moderate or high physical activity classifications (less than 600 MET-minutes/week).

\section{Statistics}

All statistical analyses were performed using STATISTICA software, v. 10.0 (StatSoft Poland). Frequency counts, means and standard deviations (SDs) were calculated for each university's participants as a whole (Turkey and Poland) and between genders (Turkish males, Turkish females, Polish males, and Polish females). Significant differences between groups ( $p \leq 0.05$ ) were assessed using Mann-Whitney $U$ tests. In addition, correlation coefficients between variables were calculated using the Spearman test. 


\section{Results}

Our findings show that $52 \%$ of all participants exhibited high physical activity levels, $37 \%$ exhibited moderate physical activity levels, and $11 \%$ exhibited low physical activity levels.

In general, Polish students were more physically active than Turkish students. More than half (78\%) of Polish students exhibited a "high" level of physical activity, the most prevalent among all of the subgroups, while only $2 \%$ of Polish students exhibited a "low" level of physical activity. In comparison, $26 \%$ of Turkish students showed a "high" level of physical activity while $20 \%$ of the Turkish students showed a "low" level of physical activity. "Moderate" levels of physical activity were higher amongst Turkish students (54\%) than Polish students (20\%) (Figure 1).

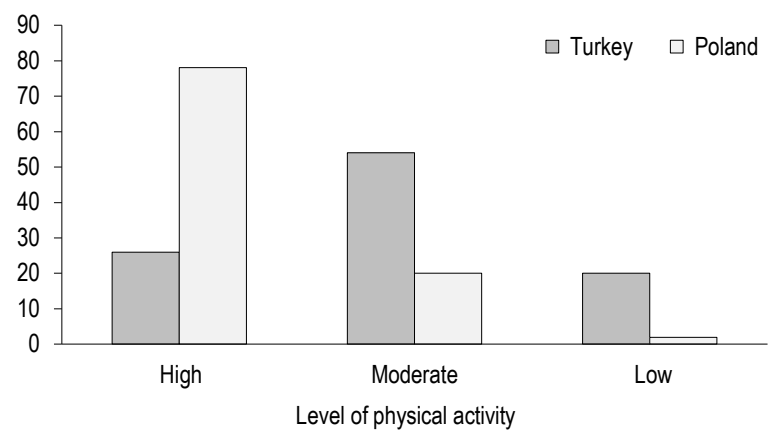

Figure 1. Physical activity levels of Polish and Turkish university students, expressed in Metabolic Equivalent of Task units (METminutes/week) using IPAQ (short-form) questionnaire data (\%)
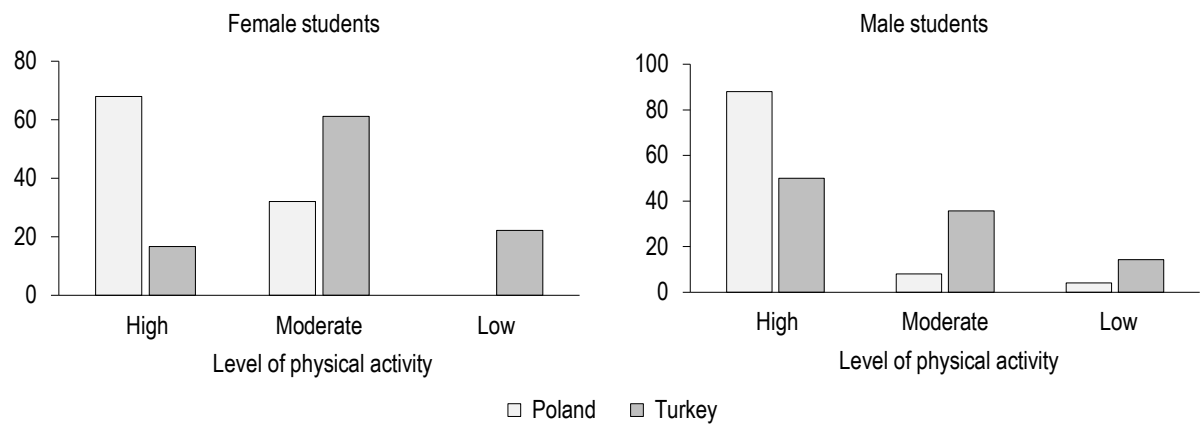

Figure 2. Physical activity levels of Turkish and Polish university students, grouped by gender, expressed in Metabolic Equivalent of Task units (MET-minutes/week) using IPAQ (short-form) questionnaire data (\%)

Physical activity data, classified by gender, also differed between nationalities (Figure 2). Polish females (68\%) and Polish males (88\%) were more engaged in "high-level" physical activity compared to Turkish females (17\%) and Turkish males (50\%). However, Turkish females (61\%) and Turkish males (38\%) were more engaged in 
"moderate-level" physical activity than Polish females (32\%) and Polish males (8\%). Polish students $(0 \%$ female; $4 \%$ male) were less likely to exhibit "low" levels of physical activity than Turkish students ( $22 \%$ female; $14 \%$ male).

Overall, Polish students exercised significantly more $(p<0.05)$ in total than Turkish students (Table 2). The mean sum of exercise for Polish students was 5,953.51 MET-minutes/week compared to 3,095.45 METminutes/week for Turkish students. Both "moderate" and "high" levels of physical activity as measured in METminutes/week were significantly different $(p<0.05)$ between nationalities. "Low" levels of physical activity (i.e. walking) were not significantly different between nationalities.

Tahle 2. The level of physical activity of university students in Poland and Turkey expressed in MET-minutes/week. Bolded p-values denote statistical significance $(p<0.05)$

\begin{tabular}{|c|c|c|c|c|c|c|c|c|}
\hline \multirow{2}{*}{ Physical activity } & \multicolumn{2}{|c|}{ Vigorous - intensity } & \multicolumn{2}{|c|}{ Moderate - intensity } & \multicolumn{2}{|c|}{ Walking } & \multicolumn{2}{|c|}{ Total } \\
\hline & Poland & Turkey & Poland & Turkey & Poland & Turkey & Poland & Turkey \\
\hline Mean & 2,701 & 814 & 1,006 & 384 & 2,246 & 1,897 & 5,954 & 3,095 \\
\hline Standard dev & 2,580 & 1,678 & 1,143 & 950 & 1,642 & 1,680 & 3,815 & 2,734 \\
\hline Median & 2,160 & 0 & 660 & 0 & 2,574 & 1,386 & 5,289 & 2,772 \\
\hline Min & 0 & 0 & 0 & 0 & 0 & 10 & 990 & 10 \\
\hline Max & 10,080 & 7,200 & 5,040 & 3,600 & 6,930 & 8,316 & 19,278 & 11,100 \\
\hline $\mathrm{p}$-value & \multicolumn{2}{|c|}{$<0.0001$} & \multicolumn{2}{|c|}{$<0.0001$} & \multicolumn{2}{|c|}{0.298} & \multicolumn{2}{|c|}{0.0001} \\
\hline
\end{tabular}

Physical activity contrasts were further exemplified between genders. Polish women engaged in significantly more $(p<0.05)$ total physical activity than Turkish women (Table 3 ). Polish women were significantly more engaged in high-level physical activity than Turkish women, yet they were significantly less engaged in moderate levels of physical activity $(p<0.05)$. Total physical activity, high-level physical activity, and moderate-level physical activity differences were not significant $(p<0.05)$ between Polish and Turkish men (Table 4). Low-level physical activity differences were not significant $(p<0.05)$ between nationalities for either gender.

Table 3. The level of physical activity of female university students in Poland and Turkey expressed in MET-minutes/week. Bolded $p$-values denote statistical significance $(p<0.05)$

\begin{tabular}{|c|c|c|c|c|c|c|c|c|}
\hline \multirow{2}{*}{ Physical activity } & \multicolumn{2}{|c|}{ Vigorous - intensity } & \multicolumn{2}{|c|}{ Moderate - intensity } & \multicolumn{2}{|c|}{ Walking } & \multicolumn{2}{|c|}{ Total } \\
\hline & Poland & Turkey & Poland & Turkey & Poland & Turkey & Poland & Turkey \\
\hline Mean & 2,224 & 400 & 1,110 & 235 & 2,264 & 1,904 & 5,599 & 2,539 \\
\hline Standard dev & 2,776 & 1,270 & 1,305 & 730 & 1,501 & 1,802 & 4,514 & 2,244 \\
\hline Median & 1,920 & 0 & 720 & 0 & 2,376 & 1,386 & 4,758 & 2,376 \\
\hline Min & 0 & 0 & 0 & 0 & 198 & 10 & 990 & 10 \\
\hline Max & 10,080 & 5,760 & 5,040 & 3,360 & 4,158 & 8,316 & 19,278 & 9,564 \\
\hline$p$-value & \multicolumn{2}{|c|}{$<0.0001$} & \multicolumn{2}{|c|}{$<0.0001$} & \multicolumn{2}{|c|}{0.253} & \multicolumn{2}{|c|}{0.001} \\
\hline
\end{tabular}

Among some students, "low-level" physical activity (i.e. walking) was the predominant component of physical activity. This was particularly evident among female Turkish students, whose ratio of the correlation value of walking (MET-minutes/week) to total physical activity (MET-minutes/week) was mostly positive and statistically significant ( $p$ $<0.05$ ), especially at low and moderate physical activity levels (Table 5). Male Turkish students, who exhibited "high" 
levels of physical activity, showed similar significant differences in the ratio of their correlation value of walking (MET-minutes/week) compared to total physical activity (MET-minutes/week).

Table 4. The level of physical activity of male university students in Poland and Turkey expressed in MET-minutes/week

\begin{tabular}{|c|c|c|c|c|c|c|c|c|}
\hline \multirow{2}{*}{ Physical activity } & \multicolumn{2}{|c|}{ Vigorous - intensity } & \multicolumn{2}{|c|}{ Moderate - intensity } & \multicolumn{2}{|c|}{ Walking } & \multicolumn{2}{|c|}{ Total } \\
\hline & Poland & Turkey & Poland & Turkey & Poland & Turkey & Poland & Turkey \\
\hline Mean & 3,178 & 1,880 & 902 & 769 & 2,228 & 1,878 & 6,308 & 4,527 \\
\hline Standard dev & 2,327 & 2,139 & 969 & 1,322 & 1803 & 1,377 & 3,013 & 3,398 \\
\hline Median & 3,200 & , 1080 & 540 & 0 & 2,772 & 1,683 & 5,493 & 4,161 \\
\hline Min & 0 & 0 & 0 & 0 & 0 & 10 & 1,200 & 33 \\
\hline Max & 10,080 & 7,200 & 3,600 & 3,600 & 6,930 & 4,620 & 14,532 & 11,100 \\
\hline$p$-value & \multicolumn{2}{|c|}{0.069} & \multicolumn{2}{|c|}{0.183} & \multicolumn{2}{|c|}{0.759} & \multicolumn{2}{|c|}{0.092} \\
\hline
\end{tabular}

Table 5. Correlation between walking and total physical activity in MET-minutes/week in Polish and Turkish university females relative to different levels of physical activity. Bolded $p$-values denote statistical significance $(p<0.05)$

\begin{tabular}{lccccccccc}
\hline \multirow{2}{*}{ Physical activity } & \multicolumn{3}{c}{ All women } & \multicolumn{3}{c}{ Turkey } & \multicolumn{3}{c}{ Poland } \\
\cline { 2 - 10 } & $\mathrm{LA}^{*}$ & $\mathrm{MA}^{*}$ & $\mathrm{HA}^{*}$ & $\mathrm{LA}^{*}$ & $\mathrm{MA}^{*}$ & $\mathrm{HA}^{*}$ & $\mathrm{LA}^{*}$ & $\mathrm{MA}^{*}$ & $\mathrm{HA}^{*}$ \\
\hline Walking MET-min/week & 0.859 & 0.835 & 0.119 & 0.859 & 0.959 & -0.115 & $\mathrm{X}^{*}$ & -0.167 & 0.081 \\
p-value & $\mathbf{0 . 0 0 6}$ & $<0.0001$ & 0.587 & $\mathbf{0 . 0 0 6}$ & $<0.0001$ & 0.826 & $\mathrm{X}^{*}$ & 0.691 & 0.755 \\
\hline
\end{tabular}

* LA - low activity (i.e. walking); MA - moderate activity; HA - high activity; X - no data

Tahle 6. Correlation between walking and total physical activity in MET-minutes/week in Polish and Turkish males relative to different levels of physical activity. Bolded $p$-values denote statistical significance $(p<0.05)$

\begin{tabular}{lccccccccc}
\hline \multirow{2}{*}{ Physical activity } & \multicolumn{3}{c}{ All men } & \multicolumn{3}{c}{ Turkey } & \multicolumn{3}{c}{ Poland } \\
\cline { 2 - 20 } & $\mathrm{LA}^{*}$ & $\mathrm{MA}^{*}$ & $\mathrm{HA}^{*}$ & $\mathrm{LA}^{*}$ & $\mathrm{MA}^{*}$ & $\mathrm{HA}^{*}$ & $\mathrm{LA}^{*}$ & $\mathrm{MA}^{*}$ & $\mathrm{HA}^{*}$ \\
\hline Walking MET-min/week & -0.577 & 0.678 & 0.607 & $\mathrm{X}^{*}$ & 0.900 & 0.889 & $\mathrm{X}^{*}$ & 0.5481 \\
p-value & 0.666 & 0.093 & $<0.0001$ & $\mathrm{X}^{*}$ & 0.373 & 0.007 & $\mathrm{X}^{*}$ & $\mathrm{X}^{*}$ & 0.888 \\
\hline
\end{tabular}

* LA - low activity (i.e. walking); MA - moderate activity; HA - high activity; X - no data.

\section{Discussion}

Our study was conducted using the short version of the International Physical Activity Questionnaire (IPAQ). The IPAQ is the most widely used and comprehensive evaluation tool that accounts for all domains of moderate and vigorous exercise (e.g. exercise performed during leisure time, work, transportation, etc.) (Brown et al., 2004; Abu-Omar, Rütten, Robine, 2004; Rütten et al., 2003).

The average level of total physical activity was higher for Polish men (6,308 MET-minutes/week), than for Polish women (5,599 MET). Turkish students, particularly women, declared much lower levels of physical activity compared to Polish students (2,539 MET for women and 4,527 MET for men). However, our study may be slightly confounded since our relatively small sample size of students was taken from university programs focused on 
physical education and recreation. Students were also asked to self-report their activity levels, a technique that inherently introduces a certain level of bias.

Our results are consistent with findings from other authors. A study by Suğuksu (2011) comparing Polish and Turkish students showed that Polish students (3,720 MET for women and 5,045 MET for men) had higher physical activity levels than Turkish students (1,690 MET for women and 2,590 MET for men). Haase et al. (2004) found similar results and exhibited that Central and Eastern European university students were more active during their leisure time (70\% of students) than Mediterranean students ( $61 \%$ of students). Variations in physical activity levels between cultures may be driven by a complex suite of interwoven socioeconomic development, technology, and urbanization factors. Perceptions of external sociological barriers, such as prioritization of academics over exercise and a perceived paucity of time due to a busy schedule and responsibilities related to family and social environment, likely play a key role in dictating university students' physical activity patterns (Daskapan, Emine, Levent, 2006).

An individual's level of physical activity can significantly contribute to the onset of both obesity and cardiovascular disease. It is imperative to assess physical activity levels to better understand the association between physical activity and health. Yet this can be a hurdle when comparing results among different sociooccupational and cultural groups, as methods and terminologies often vary.

In 2010, the World Health Organization (WHO) published guidelines on the minimum level of physical activity required to preserve human health (Global Recommendations on Physical Activity for Health). The minimum level of physical activity recommended by the WHO for adults is 150 minutes of moderate physical activity per week, or 75 minutes of vigorous physical activity per week, or an equivalent combination of vigorous and moderate physical activity. Our findings showed that $94 \%$ of Polish students ( $92 \%$ of women and $96 \%$ of men) and $40 \%$ of Turkish students ( $28 \%$ of women and $79 \%$ of men) reached or exceeded the recommended minimum of 75 minutes of vigorous physical activity per week, or an equivalent combination of vigorous and moderate physical activity per week.

While culture remains an important indicator of physical activity engagement, gender may also play a pivotal role. A study comparing physical activity levels between Czech students at the University of Olomouc with Chinese students from the University of Beijing, also found that men were generally more engaged in physical activity than women. Czech men engaged in 6,456 MET-minutes/week compared to 5,296 MET-minutes/week for women, while Chinese men engaged in 2,843 MET-minutes/week compared to 1,982 MET-minutes/week for women (Zhao, Sigmund, Sigmundová, Lu, 2007).

Other Polish literature has supported our findings that women engage in less physical activity than men (Bergier, Stępień, Niźnikowska, Bergier, 2014; Sokołowski, 2008). Similar results were also found in Brazil (Florindo et al., 2009), several member states of the Gulf Cooperation Council (Mabry, Reeves, Eakin, Owen, 2010), Jordan (Ammouri, Neuberger, Nashwan, Al-Haj, 2007), Turkey (Karaca, Caglar, Cinemre, 2009), and China (Zhao, Sigmund, Sigmundová, Lu, 2007).

Additionally, a study on physical activity that spanned 20 countries exhibited similar conclusions. Men, particularly at the university level, self-reported more physical activity than women. In general, physical activity among women decreased with age. Approximately $50 \%$ of women younger than 20 years-old were not physically active enough to meet the WHO minimum requirement needed to preserve human health. As female ages increased, the percentage of those meeting the WHO minimum requirement dropped proportionately (Bauman et al., 2009). WHO (2013) later published a study that showed physical inactivity was consistently higher among 
women (34\%) than men (28\%) across cultures. Differences in physical activity levels among genders may be driven by perception of an overarching exercise. A review of 51 cross-sectional studies elucidated that men were more positively associated with physical activity (Van der Horst, Paw, Twisk, Van Mechelen, 2007). Other studies have exhibited that physical activity levels among adolescent and university males are generally higher than those of adolescent and university females (Daskapan, Emine, Levent, 2006; El-Gilany, Badawi, El-Khawaga, Awadalla, 2011; Irwin, 2004). In Mediterranean cultures, in particular, social pressures historically linked to masculinity, such as power and athleticism, and to femininity, such as avoidance of vigorous activity and physical sports, may also contribute to gender disparities related to physical activity levels (Shafy, 1998).

The type of university students enroll in may also be indicative of their physical activity habits. Our results indicate that students enrolled at sports-centric universities may have higher levels of physical activity than students enrolled at traditional universities, where physical education faculties are not the central focus of education. This may be explained by the overarching mentality and culture of students enrolled at sports-centric universities, who may place greater emphasis on physical activity, and may have better access to exercise programs and facilities.

Here, we've shown that physical activity habits vary by both culture and gender. Our study exhibits current physical activity habits among university students in disparate cultures. This study can be utilized to improve methods for encouraging students to actively participate in physical activity. A better understanding of the underlying mechanisms that dictate physical activity decisions across cultures is needed to facilitate the development of local and international health programs.

\section{Conclusions}

1. Polish university students engage in more physical activity than Turkish students.

2. More than half of Turkish students do not meet the World Health Organization's minimum weekly physical activity recommendations for preserving health.

3. Polish university students engage in more vigorous physical activity while Turkish university students engage in more moderate physical activity.

4. Female Polish university students engage in more vigorous and moderate intensity exercise than female Turkish university students by a large margin.

5. Walking is a significant contributor to physical activity habits in Poland and Turkey.

\section{References}

Abu-Omar, K., Rütten, A., Robine, J.M. (2004). Self-rated health and physical activity in the European Union. Social and Preventive Medicine, 49, 235-242.

Ammouri, A.A., Neuberger, G., Nashwan, A.J., Al-Haj, A.M. (2007). Determinants of self-reported physical activity among Jordanian adults. Journal of Nursing Scholarship, 39 (4), 342-348.

Bauman, A., Bull, F., Chey, T., Craig, C.L., Ainsworth, E.B., Sallis, J.F., Bowles, H.R., Hagstromer, M., Sjostrom, M., Pratt, M., The IPS Group. (2009). The International Prevalence Study on Physical Activity: results from 20 countries. International Journal of Behavioral Nutrition and Physical Activity, 6, 21. DOI:10.1186/1479-5868-6-21.

Bergier, B., Stępień, E., Niźnikowska, E., Bergier, J. (2014). Aktywność fizyczna kobiet i mężczyzn studiujących w Państwowej Szkole Wyższej w Białej Podlaskiej. Medycyna Ogólna i Nauki o Zdrowiu, 20 (2), 166-170.

Booth, M.L. (2000). Assessment of Physical Activity: An International Perspective. Research Quarterly for Exercise and Sport, 71 , 114-120. DOI: 10.1080/02701367.2000.11082794. 
Brown, W.J., Trost, S.G., Bauman, A., Mummery, K., Owen, N. (2004). Test-retest reliability of four physical activity measures used in population surveys. Journal of Science and Medicine in Sport, 7, 205-215.

Bruunsgaard, H. (2005). Physical activity and modulation of systemic low-level inflammation. The Journal of Cell Biology, 78, 1-17. DOI: 10.1189/jlb.0505247.

Craig, C.L., Marshall, A.L., Sjøstrom, M., Bauman, A.E., Booth, M.L., Ainsworth, B.E., Pratt, M., Ekelund, U., Yngve, A., Sallis, J.F., Oja, P. (2003). International Physical Activity Questionnaire: 12-country reliability and validity. Medicine and Science in Sports and Exercise, 35, 1381-1395. DOI: 10.1249/01.MSS.0000078924.61453.FB.

Daskapan, A., Emine, H.T., Levent, E. (2006). Perceived Barriers to Physical Activity in University Students. Journal of Sports Science and Medicine, 5, 615-620.

Drygas, W., Jegier, A., Bednarek-Gejo, A., Kostka, T. (2005). Long-term effects of various physical activity levels in preventing obesity an metabolic syndrome in Middle-aged men. The European Journal of Cardiovascular Prevention and Rehabilitation, 12, 28-34.

El-Gilany, A.H., Badawi, K., El-Khawaga, G., Awadalla, N. (2011). Physical activity profile of students in Mansoura University, Egypt. Eastern Mediterranean Health Journal, 17 (8), 694-702.

Florindo, A.A., Guimarães, V.V., Caesar, C.L.G., Barros, M.B.A., Alves, M.C.G.P., Goldbaum, M. (2009). Epidemiology of leisure, transportation, occupational, and household physical activity: Prevalence and associated factors. Journal of Physical Activity and Health, 6, 625-632.

Haase, A., Steptoe, A., Sallis, J.F., Wardle, J. (2004). Leisure-time physical activity in university students from 32 countries: associations with health beliefs, risk awareness and national economic development. Preventive Medicine, 39 (1), 182-190.

Haskell, W.L., Lee, I.M., Pate, R.R., Powell, K.E., Blair, S.N., Franklin, B.A., Macera, CA., Heath, GW., Thompson, PD., Bauman, A. (2007). Physical activity and public health: updated recommendation for adults from the American College of Sports Medicine and the American Heart Association. Medical and Science in Sports and Exercise, 39 (8), 1423-1434. DOI: 10.1249/ mss.0b013e3180616b27.

Irwin, J.D. (2004). Prevalence of university students' sufficient physical activity: a systematic review. Perceptual and Motor Skills, 98 (1), 927-943.

Janssen, I., Leblanc, A.G. (2010). Systematic review of the health benefits of physical activity and fitness in school-aged children and youth. International Journal of Behavioral Nutrition and Physical Activity, 7, 40-56. DOI: 10.1186/1479-5868-7-40.

Karaca, A., Caglar, E., Cinemre, S.A. (2009). Physical activity levels of the young adults in an economically developing country: The Turkish sample. Journal of Human Kinetics, 22, 91-98.

Katzmarzyk, P.T., Church, T.S., Craig, C.L., (2009). Bouchard C. Sitting time and mortality from all causes, cardiovascular disease, cancer. Medical and Science in Sports and Exercise, 41, 998-1005. DOI: 10.1249/MSS.0b013e3181930355.

Mabry, R.M., Reeves, M.M., Eakin, E.G., Owen, N. (2010). Evidence of physical activity participation among men and women in the countries of the Gulf Cooperation Council: a review. Obesity Review,11, 457-464.

Malina, R.M., Katzmarzyk, P.T. (2006). Physical activity and fitness in an international growth standard for preadolescent and adolescent children. Food and Nutrition Bulletin, 27 (5), 295-313.

Mussino, A. (1999). Conceptual and operational problems in measuring participation in Sports. Bulletin 52nd Session of the International Statistical Institute. Helsinki.

Narring, F., Cauderay, M., Cavadini, C., Michaud, P.A. (1999). Physical fitness and sport activity of children and adolescents: methodological aspects of a regional survey. Social and Preventive Medicine, 44, 44-54. DOI: 10.1007/BF01667126.

Nelson, M.E., Rejeski, W.J., Blair, S.N., Duncan, P.W., Judge, J.O., King, A.C., Macera, C.A., Castaneda-Sceppa, C. (2007). Physical activity and public health in older adults: recommendation from the American College of Sports Medicine and The American Heart Association. Medical and Science in Sports and Exercise, 39 (8), 1435-1445. DOI: 10.1161/CIRCULATIONAHA.107.185650.

Penedo, F.J., Dahn, J.R. (2005). Exercise and Well-Being: A review of mental and physical health benefits associated with physical activity. Current Opinion in Psychiatry, 18 (2), 189-193.

Rütten, A., Vuillemin, A., Ooijendijk, W.T., Schena, F., Sjostrom, M., Stahl, T., Vanden Auweele, Y., Welshman, J., Ziemainz, H. (2003). Physical activity monitoring in Europe. The European Physical Activity Surveillance System (EUPASS) approach and indicator testing. Public Health Nutrition, 6, 377-384.

Shafy, H.E. (1998). Leisure time and its implication. In: Adolescence and state policy in Egypt, Ch VI. Cairo, Egypt, The Population Council. Regional Office for West Asia and North Africa.

Sokołowski, M. (2008). Międzynarodowy Kwestionariusz Aktywności Fizycznej (IPAQ) jako miernik oceny aktywności fizycznej studentów Akademii Wychowania Fizycznego. In: E. Szczepanowska, M. Sokołowski, (eds.), Aktywność fizyczna i odżywianie 
się, jako uwarunkowania promocji zdrowia (pp. 113-124). Poznań: Wielkopolska Wyższa Szkoła Turystyki i Zarządzania w Poznaniu.

Suğuksu, K. (2011). Physical activity level between Polish and Turkish university students (IPAQ). In: B. Bergier (ed.), Physical activity in health and disease (pp. 19-27). Biała Podlaska: Pope John Paul II State School of Higher Education in Biała Podlaska.

Touvier, M., Bertrais, S., Charreire, H., Vergnaud, A.C., Hercberg, S., Oppert, J.M. (2010). Changes in leisure-time physical activity and sedentarny behaviour at retirement: a prospective study in Middle-aged French subjects. International Journal of Behavioral Nutrition and Physical Activity, 7, 14. DOI: 10.1186/1479-5868-7-14.

Van Bottenburg, M., Rijnen, B., van Sterkenburg, J. (2005). Sports participation in the European Union. Trends and differences. Nieuwegein/'sHertogenbosch: Arko Sports Media/W.J.H. Mulier Institute.

Van der Horst, K., Paw, M., Twisk, J.W., Van Mechelen, W. (2007). A brief review on correlates of physical activity and sedentariness in youth. Medicine and Science in Sport and Exercise, 39 (8), 1241-1250.

WHO 2013. Global Health Observatory, Prevalence of insufficient Physical activity. Retreived from http://www.who.int/gho/ncd/risk_ factors/physical_activity_text/en (July 2014).

www.ess.nsd.uib.no.

www.healthcanada.ca/paguide Handbook for Canada's physical activity guide to healthy active living, Health Canada, Canadian Society for Exercise Physiology.

www.ipaq.ki.se.

Zhao, Y., Sigmund, E., Sigmundová, D., Lu, Y. (2007). Comparison of physical activity between Olomouc and Beijing university students using an International Physical Activity Questionnaire. Acta Universitatis Palackianae Olomucensis. Gymnica, 37 (4), $107-114$.

Zatoński, W.A, (2011). HEM Project team. Epidemiological analisys of health situation development in Europe and its causes until 1990. Annals of Agriculture and Environmental Medicine, 18 (2), 194-202.

Zoeller, F.R.Jr. (2007). Physical activity and obesity: their interaction and implications for disease risk and the role of physical activity in healthy weight management. American Journal of Lifestyle Medicine, 1 (6), 437-446. DOI: 10.1177/1559827607306889.

Cite this article aS: Bednarek, J., Pomykała, S., Bigosińska, M., Szyguła, Z. (2016). Physical Activity of Polish and Turkish University Students as Assessed by IPAQ. Central European Journal of Sport Sciences and Medicine, 16 (4), 13-22. DOI: 10.18276/cej.2016.4-02. 